\title{
Incidental Solar Radiation According to the Solar Collector Slope - Horizontal Measurements Conversion on an Inclined Panel Laws
}

\author{
Romdhane Ben Slama*
}

Department of Electromecanique, ISSAT Gabès 6029 Gabès Tunisia

\begin{abstract}
In this article we are interested in the optimal choice of the tilt angle of solar water heaters, in the case of Tunis (lat $36^{\circ} .85$, long $10^{\circ} .2$ ). We studied several variations of usage months: spread all year round or solely reduced for some months: nine, seven or five months centered on winter - the most difficult period to satisfy in term of solar energy. Results show that a more elevated tilt of the collector for some degrees in relation to the latitude of the place [1] is essential especially if we want to make favorable the conditions of collecting in winter where resources in solar energy are at their minimum, whereas, the needs in hot water are at their maximum. In a second part of this article, means of conversion are given, for a collector plane tilt of an angle " $i$ ", of the solar data of the received global and diffuse solar radiation by the horizontal plane. The results are resemble those of to Duffie [2] but the correlation is shorter. Thus, we can help laboratories which are not equipped with measure devices of solar energy; an apparent data to determine performances of all solar energy conversion system or using it as primary energy source. We can rely on solar data which will be converted according to both the tilt angle and the orientation of the solar panels.
\end{abstract}

Keywords: Solar radiation, solar collector, tilt, horizontal measurements, conversion.

\section{INTRODUCTION}

Beginning, with the observation that the solar water heaters are heated too much in summer, but are unsatisfactory in winter, so the need for an augmentation is apparent. In addition, considering the increased interest of the knowledge of the incidental radiation solar on a solar collector in order to determine its performances, as well as the interest of the inclination angle optimization of the collector according to the desired use of the collector, many papers were published for various countries of the world [3-18].

Following authors: Singri [8], Yakup [10], Elminir [17] and Tang [19], was use for the south facing collector a same simplified correlation (1):

$R_{b}=\frac{\cos (\delta) \cdot \sin \left(\omega_{0}\right) \cdot \cos (\lambda-\theta)+\omega_{0} \cdot \sin (\delta) \cdot \sin (\lambda-\theta)}{\cos (\delta) \cdot \sin \left(\omega_{0}\right) \cdot \cos (\lambda)+\omega_{0} \cdot \sin (\delta) \cdot \sin (\lambda)}$

representing the geometric factor which is the ratio of the beam radiation and the tilted surface to that on a horizontal at any time.

For the optimal tilt angle « $\mathrm{i} »$, the authors Singri [8], Duffie-Beckman [2] and Elminir [17] suggested to chose it equal to local latitude $\varphi$ plus $15^{\circ}$ in winter and minus $15^{\circ}$ in summer.

The present article is published for Tunisia [20] to determine the incidental solar energy on a collector for various slopes and with various orientations, which can be generalized with the solar water, photovoltaic panel and air collectors, but also with the walls of a building.

*Address correspondence to this author at the ISSAT Gabès 6029 Gabès Tunisia; Tel: +216 9866000 7; Fax: +216 75392 390;

E-mail: Romdhane.BenSlama@issatgb.rnu.tn
The conversion of global and diffuse solar radiation on a horizontal to a tilted plane is also treated by Ben Slama [21, 22]. In fact we have found a more simple correlation than other authors, such as Duffie \& Beckman [2].

\section{COMPUTATION MODEL}

To know the solar energy received per day by an inclined plane collector of an angle " $\mathrm{i}$ " compared to the horizontal one, the following sizes are successively computed using the Bernard-Menguy-Schwartz model [4] , checked in appendix:

- the height of the sun at true solar midday

$\mathrm{h}=90-\varphi+\delta(\mathrm{t})$

The variation of the sun $\delta(t)$ is equal to the latitude of the place located between the tropics and for which the solar rays are perpendicular to the horizontal plane at solar midday. Table $\mathbf{1}$ gives the monthly average of the variation.

Table 1. Monthly Average Solar Declination

\begin{tabular}{|c|c|c|c|c|c|c|}
\hline Month & January & February & March & April & May & June \\
\hline \hline$\delta(t)$ & -20.8 & -12.7 & +1.9 & +9.9 & +18.9 & +23.1 \\
\hline Month & July & August & September & October & $\begin{array}{c}\text { Novem- } \\
\text { ber }\end{array}$ & $\begin{array}{c}\text { Decem- } \\
\text { ber }\end{array}$ \\
\hline$\delta(t)$ & +21.3 & +13.7 & +3.0 & -8.8 & -18.4 & -23.0 \\
\hline
\end{tabular}

- the angle "u" formed between the normal of the collector and the solar rays at solar midday:

$\mathrm{u}=90-(\mathrm{i}+\mathrm{h})$

- the direct radiation (i.e. coming directly from the sun and not from the atmosphere), under three conditions of clear sky: 
- clear sky

$I_{D}=1230 . \exp \left(\frac{-1}{3.8 \sin (h+1.6)}\right)$

- $\quad$ very clear sky

$I_{D}=1210 \cdot \exp \left(\frac{-1}{6 \sin (h+1)}\right)$

- $\quad$ polluted sky

$I_{D}=1260 . \exp \left(\frac{-1}{2.3 \sin (h+3)}\right)$

- the diffused radiation (i.e., emitted or reflected by the atmosphere, the clouds... received by the horizontal plane in the three cases of sky:

- clear sky

$D_{H}=125 .(\sin (h))^{0.4}$

- very clear sky

$D_{H}=125 .(\sin (h))^{0.4}$

- polluted sky

$D_{H}=125 .(\sin (h))^{0.4}$

- the total radiation received by the horizontal plane:

$G_{H}=D_{H}+I_{D} \cdot \sin (h)$

- diffuse and total radiations receipts by the inclined collector plane:

$\mathrm{D}_{(\mathrm{i})}=\frac{1+\cos (\mathrm{i})}{2} \cdot \mathrm{D}_{\mathrm{H}}+\frac{1-\cos (\mathrm{i})}{2} \cdot \mathrm{G}_{\mathrm{H}} \cdot \alpha$

$G(i)=I_{D} \cdot \cos (u)+D_{(i)}$

The albedo $\alpha$ is the coefficient of reflexion of the ground located in front of the collector (usually taken equal to 0,2 ).

- Duration of the day:

$\Delta T 0=\frac{2}{15} \cdot \arccos (-\operatorname{Tan}(\varphi) \cdot \operatorname{Tan}(\delta))$

For a solar collector directed constantly towards the south, and for the period located between the March 21 and the September 23, the duration of collecting is to be corrected by:

$\Delta T 0^{\prime}=12+\frac{\Delta T 0-12}{7}$

- finally received energy:

$W 0=\frac{2}{\pi} \cdot G(i) \cdot P$
Were $\mathrm{P}=\Delta \mathrm{T} 0$ unless date between March 21 to Sept 22 , where $\mathrm{P}=\Delta \mathrm{T} 0$ '

\section{RESULTS AND DISCUSSIONS}

\subsection{Ideal Tilt Angle of the Solar Collectors According to the Date}

The goal of this article is to show that the optimal angle is not inevitably the average of the slope over the year, that is to say the case of Tunis $(60+14) / 2=37^{\circ}$ which corresponds to approximately the latitude of the place. This angle depends especially on the period of use of the solar collector.

We will see hereafter that the optimal angle " $\mathrm{i}$ " can reach $55^{\circ}$ if we want to privilege the use during the winter period which spreads out over five months, from November to March.

Fig. (1) shows the variation, according to the time, which the collector tilt angle, for an optimal absorption of the solar radiation, should have. In the case of Tunis, the angle "i" varies between 14 and 60 degrees according to the date.

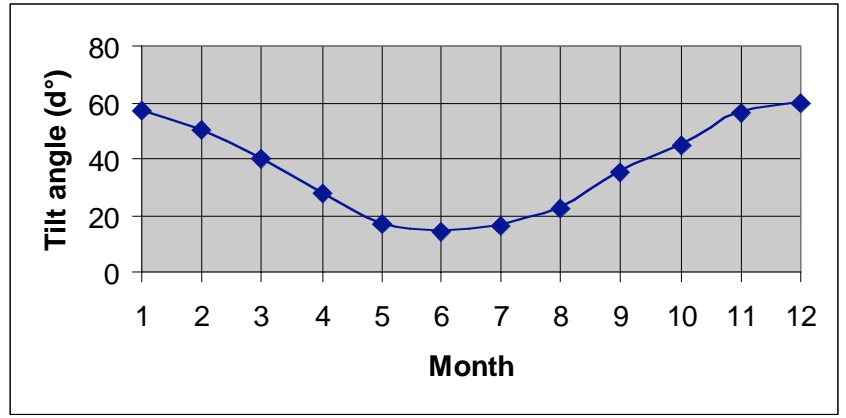

Fig. (1). Monthly average optimal slope "i" of the collector.

\subsection{Flux Received by the Collector According to the Slope and of the Period of Usage}

Fig. (2) gives the variation of the average total flux G(i) received by an inclined plane at midday, under good weather, for uses of the solar collectors being spread out over various periods.

A variation of more or less $5^{\circ}$ of the inclination angle compared to the optimal value is tolerable. Each curve indeed admits a maximum of power for this optimal value of inclination.

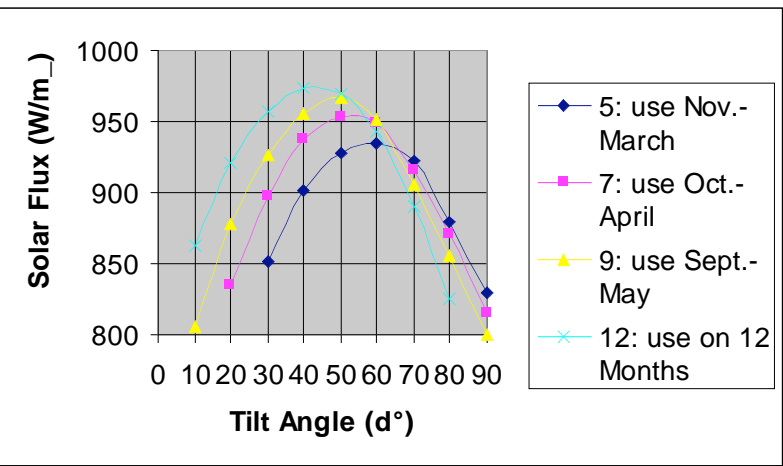

Fig. (2). Average incidental solar flux according to the collector's inclination "i", for different usage duration of $5,6,7$, and 12 months. 
We note, according to the desired period of usage of the solar collectors, that the optimal inclination with the horizontal evolves, indeed:

- If the use is spread out over all the year round (12 months), in an intense way in summer, as in winter, then the inclination of the collector must be higher than the latitude of the place of approximately $5^{\circ}$ in order to profit as much as possible from the albedo contributions. Perhaps Chauliagué [23] neglected this point. Thus for Tunis, the angle inclination should move from 37 to $42^{\circ}$ (Fig. 2).

- On the other hand, if the usage consists of the heating of domestic water, three months (from June to August) will be omitted from the period of use, because in summer, the weather is very warm in Tunisia and the hot water needs are at their minimum. The optimum of incidental flux for the nine other months is obtained for an inclination in around $50^{\circ}$, In summer, even with a very high slope of the collector $\left(50^{\circ}\right.$ instead of $20^{\circ}$ ), water heats well because the thermal losses towards the ambient hot air are not high, however the needs for domestic hot water are weak.

- Finally, if the use of solar energy interests the winter period only (November to March), then the optimal inclination is in the neighborhoods of $58^{\circ}$.

\subsection{Received Solar Flux by the Collector According to the Date and Various Inclinations}

Fig. (3) shows the variation of the solar flux intercepted by the collector under to various inclinations $\left(37^{\circ}, 45^{\circ}, 55^{\circ}\right.$ and 90-h).

We note that for an incidence of $45^{\circ}$, the intercepted solar flux is better than that for $36^{\circ}, 8$ during all the winter period. It is also the case for $55^{\circ}$ which is better than $45^{\circ}$ during this same period.

Thus, these two angles $\left(45^{\circ}\right.$ and $\left.55^{\circ}\right)$ offer, compared to $36^{\circ} .8$, a better arrangement of collecting from November to March, period during which the solar contributions are in their minimum. On the other hand, the arrangement becomes unfavorable in summer, but that does not prevent from obtaining sufficiently hot water in view of the so high ambient temperature in summer.

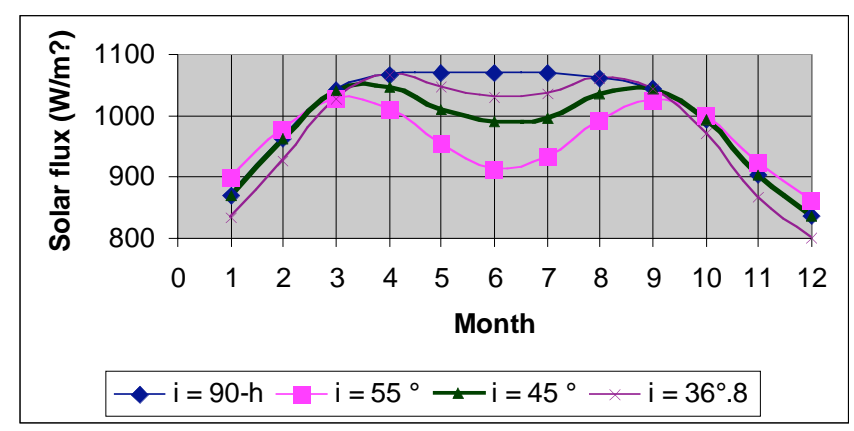

Fig. (3). Solar flux received by the collector according to the date and under various incidences.

\subsection{Energy Received According to the Date Under for Various Inclinations of the Solar Collector}

If the power curves do not give a great variation of the solar supply according to the seasons, it is not the case for the energy curves which give more significant variations; this is because of the insolation fraction which varies from winter to summer to more than $50 \%$. In fact according to Fig. (4), the energy received in August is twice as much as in December.

The $55^{\circ}$ inclination offers, in winter period, a maximum energy, whereas the $36^{\circ} .8$ angle offers a weaker energy during the same period $(-10 \mathrm{kWh})$. The latter is better during the rest of the year $(+20 \mathrm{kWh})$.

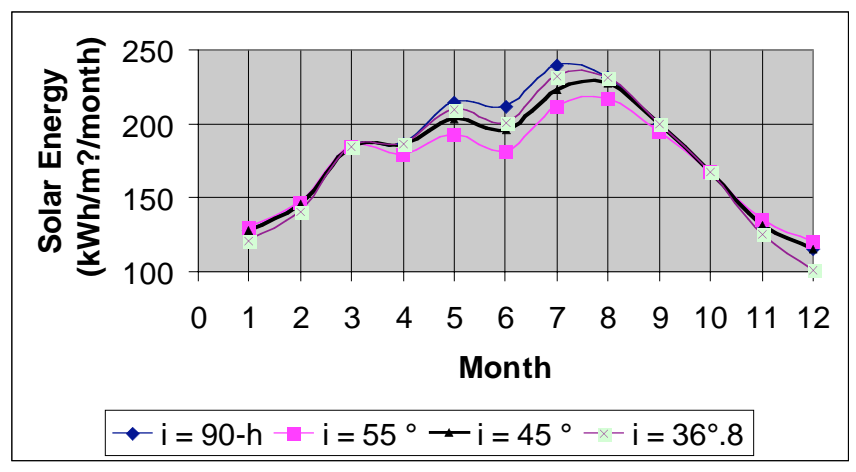

Fig. (4). Monthly received energy at Tunis for various slopes of the collector.

\subsection{Received Energy According to the Inclination of the Collector and the Period of Use}

Fig. (5) gives solar energy received per $\mathrm{m}^{2}$ of surface during various periods from5 to 12 months.

The maximum of each curve indicates a certain optimal value of the inclination angle.

If the use of the solar water heaters is spread out over all the year, which is rare, then the inclination angle can be taken near to $40^{\circ}$.

But if we want to privilege the use in winter when the climatic conditions are the most difficult, then the angle to be considered can be taken between 50 and $60^{\circ}$. The following findings confirm what was proven previously.

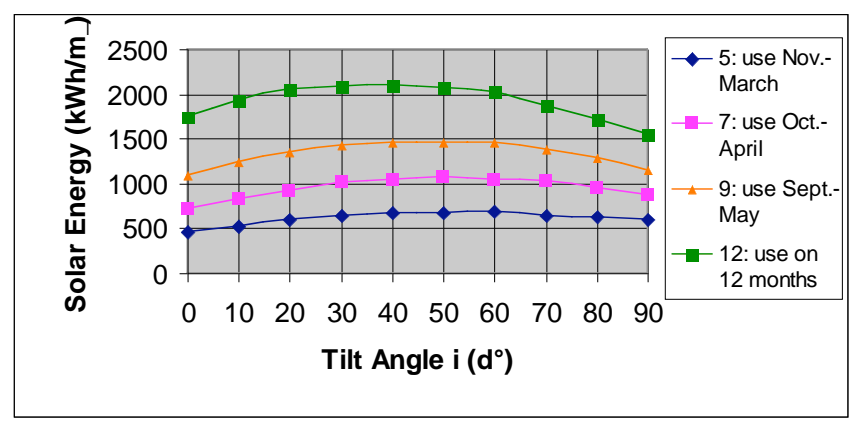

Fig. (5). Received Energy by $\mathrm{m}^{2}$ during various significant periods.

The results are in agreement with Chow 2004.

\subsection{Influence of Albedo on Received Energy}

Fig. (6) gives incidental solar energy during the five winter months (November to March) according to the albedo and tilted angle of the collector versus the horizontal. 
The optimal slope is approximately $50^{\circ}$ for an albedo of 0.1 . This inclination rises to $65^{\circ}$ for an albedo of 0.9 . Indeed, the passage of the albedo from 0.1 to 0.9 evolves an increase of the received solar energy of $10 \%$ for an inclination of $55^{\circ}$. The higher the inclination in winter, more solar flux is intercepted and more energy collected.

For periods of use more than five months, the result would be the same one, except that the optimal angle would be smaller.

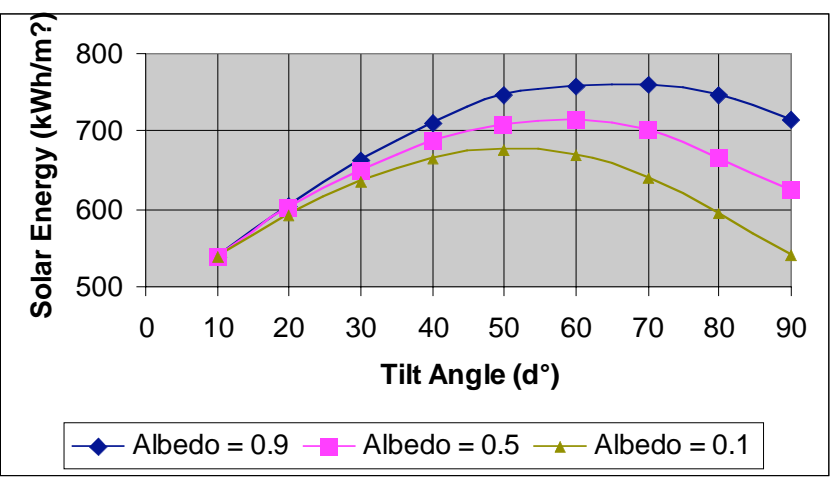

Fig. (6). Received energy during five months (November to March) according to the slope of the collector and for various albedos.

\section{CONVERSION, ON AN INCLINED COLLECTOR, OF THE HORIZONTAL MEASUREMENTS PRO- VIDED BY THE WEATHER STATIONS}

Many laboratories in the world do not have material of measurement of solar radiation received by the solar collector plane which they use in their study. However weather stations are numerous in Tunisia, as well as all over the world and that would be an attractive idea to use their measurements of global and diffused radiation received by the horizontal plane. This is all the more true when these stations are sufficiently close for them.

Two principal cases can arise [21]:

- The solar collector is constantly directed towards the sun (or at each half an hour for example), with a fixed or variable inclination.

- the collector has a fixed inclination and a constant orientation towards the south [19].

\subsection{Collector Directed Constantly Towards the Sun}

We decompose the direct solar radiation (Fig. 7) into its two components received by vertical plane IDV and horizontal IDH, which we project on the normal of the collector.
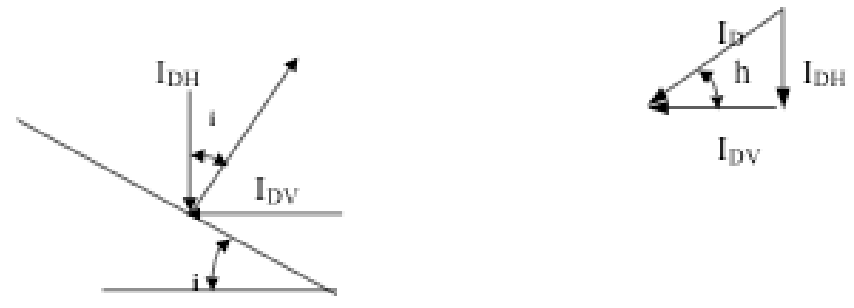

Fig. (7). Direct solar flux decomposition.
ID (i) $=$ IDH Cos (i) + IDV $\sin ($ i)

but, IDH is the difference between the global and the diffused radiation received by the horizontal plane and measured by the weather stations, that is to say:

$\mathrm{IDH}=\mathrm{GH}-\mathrm{DH}$

And since, from Fig. (7):

$I_{D V}=\frac{I_{D H}}{\operatorname{Tan}(h)}$

Then:

ID $(\mathrm{i})=(\mathrm{GH}-\mathrm{DH}) \cdot(\cos (\mathrm{i})+\sin (\mathrm{i}) / \mathrm{Tan}(\mathrm{h}))$

The global radiation received by the collector is the sum of the direct and diffused radiations, therefore:

$\mathrm{G}(\mathrm{i})=(\mathrm{GH}-\mathrm{DH}) \cdot(\cos (\mathrm{i})+\sin (\mathrm{i}) / \operatorname{tg}(\mathrm{h}))+\mathrm{D}(\mathrm{i})$

what can be written easily in the form:

$\mathrm{G}(\mathrm{i})=(\mathrm{GH}-\mathrm{DH}) \cdot(\sin (\mathrm{i}+\mathrm{h}) / \sin (\mathrm{h}))+\mathrm{D}(\mathrm{i})$

As for the height of the sun, it is given at any moment by [5]

$\sin (h)=\sin (\varphi) \cdot \sin (\delta)+\cos (\varphi) \cdot \operatorname{Cos}\left(\delta_{)}\right) \cdot \cos (\mathrm{AH})$

\subsection{Collector Fixed Orientation, Towards the South}

As previously, ID is decomposed up into $\mathrm{ID}_{\mathrm{V}}$ and $\mathrm{ID}_{\mathrm{H}}$ (Fig. 8a). We bring back vertical component $\mathrm{ID}_{\mathrm{V}}$ of solar flux in the normal plane to the collector directed towards the south (Fig. 8b) to obtain ID $_{\mathrm{Vs}}$. We make then the projection of $\mathrm{ID}_{\mathrm{H}}$ and $\mathrm{ID}_{\mathrm{VS}}$ on the normal with collector $\overrightarrow{\mathrm{n}}$ (Fig. 8c).

The Fig. (8a) permit to write: $\operatorname{tg}(\mathrm{h})=\mathrm{ID}_{\mathrm{H}} / \mathrm{ID}_{\mathrm{V}}$

The Fig. $(\mathbf{8 b})$ gives: IDVS $=\mathrm{IDV} \cos (\mathrm{a})=\mathrm{ID}_{\mathrm{H}} / \operatorname{tg}(\mathrm{h}) \cos (\mathrm{a})$

The azimuth "a" is measured in the horizontal plane, between the position of the sun at any moment and its position at solar midday. "a" is related to the time angle AH which constitutes the rotating angle of the earth of a given moment until solar midday ( $1 \mathrm{~h}$ corresponds to $15^{\circ}$ ) by:

$\sin (\mathrm{a})=\cos (\delta) \cdot \sin (\mathrm{AH}) / \cos (\mathrm{h})$

The Fig. (8c) permits to write the projection, onto the normal to the inclined plane, of $\overrightarrow{\mathrm{ID}}_{\mathrm{HS}}$ and $\overrightarrow{\mathrm{ID}}_{\mathrm{Vs}}$ :

proj. $\overrightarrow{\mathrm{ID}}_{\mathrm{HS}} / \overrightarrow{\mathrm{n}}=\mathrm{ID}_{\mathrm{HS}} \cdot \cos (\mathrm{i})=\mathrm{ID}_{\mathrm{H}} \cdot \cos (\mathrm{i})$

proj. $\overrightarrow{\mathrm{ID}}_{\mathrm{Vs}} / \overrightarrow{\mathrm{n}}=\mathrm{ID}_{\mathrm{VS}} \cdot \cos (90-\mathrm{i})=\mathrm{IDH} / \tan (\mathrm{h}) \cdot \cos (\mathrm{a}) \cdot \sin (\mathrm{i})$

from where:

$\operatorname{ID}(\mathrm{i})=\mathrm{ID}_{\mathrm{H}} \cdot(\cos (\mathrm{i})+\cos (\mathrm{a}) \cdot \sin (\mathrm{i}) / \tan (\mathrm{h}))$

and since,

$\mathrm{G}(\mathrm{i})=\mathrm{ID}(\mathrm{i})+\mathrm{D}(\mathrm{i})$ and $\mathrm{ID}_{\mathrm{H}}=\mathrm{GH}-\mathrm{DH}$

We obtain:

$\mathrm{G}(\mathrm{i})=(\mathrm{GH}-\mathrm{DH}) \cdot(\cos (\mathrm{i})+\cos (\mathrm{a}) \cdot \sin (\mathrm{i}) / \tan (\mathrm{h}))+\mathrm{D}(\mathrm{i})$

If $\mathrm{a}=0$, we find the preceding formula of $\mathrm{G}(\mathrm{i})$ where the solar collector is directed constantly towards the sun. 


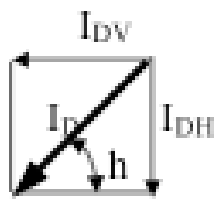

a)

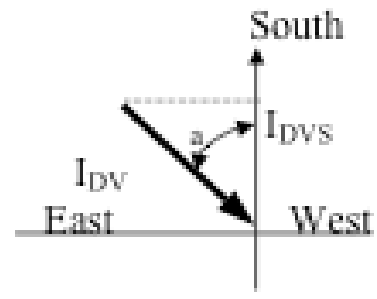

b)

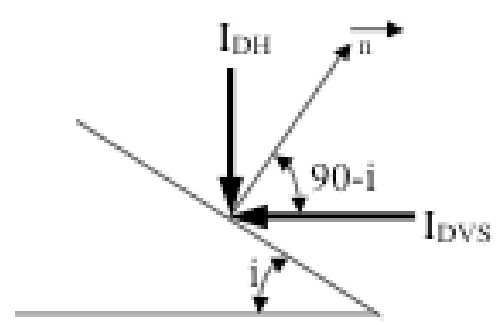

c)

Fig. (8). Components of the direct radiation, and their projections on the normal of the collector.

\section{Notice:}

In the reference [24], the following expression of ID (i) is gived:

ID (i) $=I D_{\mathrm{H}} \cdot(\sin \mathrm{H} \cdot \cos (\mathrm{i})+\cos (\mathrm{h}) \cdot \sin (\mathrm{i}) \cdot \cos (\mathrm{a})) / \sin (\mathrm{h})$

It is equivalent to ours.

However in the reference [2], we find the relation (26) quiete long:

$\operatorname{ID}(\mathrm{i})=\mathrm{IDH} \cdot(\cos (\varphi-\mathrm{i}) \cdot \cos (\delta) \cdot \cos (\mathrm{AH})+\sin (\varphi-\mathrm{i}) \cdot \sin (\delta) \cdot \cos$

$(\varphi) \cdot \cos i) \cdot \cos (\mathrm{AH})+\sin (\varphi) \cdot \sin (\delta))$

Which does not have the same expression as ours, but which gives, after checking, exactly the same result.

Hamdy and et al. [25] gives some conversion for the case study of Helsan, Egypt.

\section{CONCLUSIONS}

It is commonly assumed that the angle of inclination of a solar collector that will give optimum annual performance is approximately equal to the latitude at the given location. However preliminary observations made in this study strongly suggest that this may not be the case as illustrated in Fig. (5).

The first part of the study clearly shows that the angle of inclination taken commonly equal to the latitude of area is not correct even if the use is spread out over all the year (Fig. 5). During the broadest period of heating, which spreads out from mid-September to the end of April, the optimal inclination of the solar water heaters is of $55^{\circ}$, providing the same amount of energy as with the ideal inclination $(\mathrm{i}=90-\mathrm{h})$. In April the defect is only 5\%. The $10 \%$ decrease of incidental solar energy, by this inclination, around June is not at all a handicap, since it is a naturally hot period, and to the fact that needs in hot water weaken. On the contrary, we thus protect the collector from overheating which affects its longevity.

The second part involves the estimate of incidental solar energy. The formula, given for the calculation of received energy, have a sufficient precision to be able to adopt them when designing solar system.

For an existing photovoltaic or thermal solar installation, and to take account of the wispy cloud, the follow-up of the performances requires the measurement of incidental solar energy, failing this, we can use the closest weather stations data adopted according to conversion formula given in this present article.

\section{NOMENCLATURE}

\begin{tabular}{|c|c|c|}
\hline A & $=$ & azimuth angle $\left(^{\circ}\right)$ \\
\hline $\mathrm{AH}$ & $=$ & Solar Hour Angle $\left(^{\circ}\right)$ \\
\hline $\mathrm{D}_{\mathrm{H}}$ & $=$ & $\begin{array}{l}\text { diffused solar radiation received by the hori- } \\
\text { zontal plane }\left(\mathrm{W} / \mathrm{m}^{2}\right)\end{array}$ \\
\hline $\mathrm{D}(\mathrm{i})$ & $=$ & $\begin{array}{l}\text { diffused solar radiation received by the titled } \\
\text { collector }\left(\mathrm{W} / \mathrm{m}^{2}\right)\end{array}$ \\
\hline $\mathrm{G}_{\mathrm{H}}$ & $=$ & $\begin{array}{l}\text { global solar radiation received by the hori- } \\
\text { zontal plane }\left(\mathrm{W} / \mathrm{m}^{2}\right)\end{array}$ \\
\hline $\mathrm{G}(\mathrm{i})$ & $=$ & $\begin{array}{l}\text { global solar radiation received by the collec- } \\
\text { tor }\left(\mathrm{W} / \mathrm{m}^{2}\right)\end{array}$ \\
\hline $\mathrm{h}$ & $=$ & height of the sun at true solar midday $\left(^{\circ}\right)$ \\
\hline $\mathrm{i}$ & $=$ & solar collector slope $\left(^{\circ}\right)$ \\
\hline $\mathrm{I}_{\mathrm{D}}$ & $=$ & direct solar flux $\left(\mathrm{W} / \mathrm{m}^{2}\right)$ \\
\hline $\mathrm{Rb}$ & $=$ & $\begin{array}{l}\text { ratio of monthly collectible radiation on a } \\
\text { tilted surface to that on a horizontal surface }\end{array}$ \\
\hline $\mathrm{u}$ & $=$ & $\begin{array}{l}\text { angle formed by the normal to the collector } \\
\text { and the solar rays incident to the collector }\left(^{\circ}\right)\end{array}$ \\
\hline W0 & $=$ & $\begin{array}{l}\text { energy theorically received per } \mathrm{m}^{2} \text { and per } \\
\text { day }(\mathrm{kWh} / \mathrm{m} 2 / \mathrm{d})\end{array}$ \\
\hline$\delta(t)$ & $=$ & declination of the sun $\left(^{\circ}\right)$ \\
\hline$\varphi, \lambda$ & $=$ & latitude of the place $\left(^{\circ}\right)$ \\
\hline$\alpha$ & $=$ & albedo \\
\hline$\theta$ & $=$ & solar collector slope $\left({ }^{\circ}\right)$ \\
\hline$\sigma$ & $=$ & fraction of insolation \\
\hline$\omega_{0}$ & $=$ & hour angle $\left(^{\circ}\right)$ \\
\hline$\Delta \mathrm{T} 0$ & $=$ & length of day from sept.23 to march 20 (h) \\
\hline$\Delta \mathrm{T} 0$ & $=$ & $\begin{array}{l}\text { insolation duration from march } 21 \text { to sept. } 22 \\
\text { (h) }\end{array}$ \\
\hline
\end{tabular}




\section{APPENDIX:}

To validate the computed values according to the model of Bernard-Menguy-Schwartz, one will compare them with the data measured by the service of national meteorology as that provides by quotes Web tecsol.fr:

Town of Gabes (latitude $33^{\circ} .88$ north, 10.1est)

Horizontal plane.

A1- Comparison compared to the weather data for example for: March 21, 1996 clear sky.

The time error remains within the limit of $\pm 10 \%$ and for the whole day the computed values only exceed measurements of $1 \%$, what is very acceptable. .

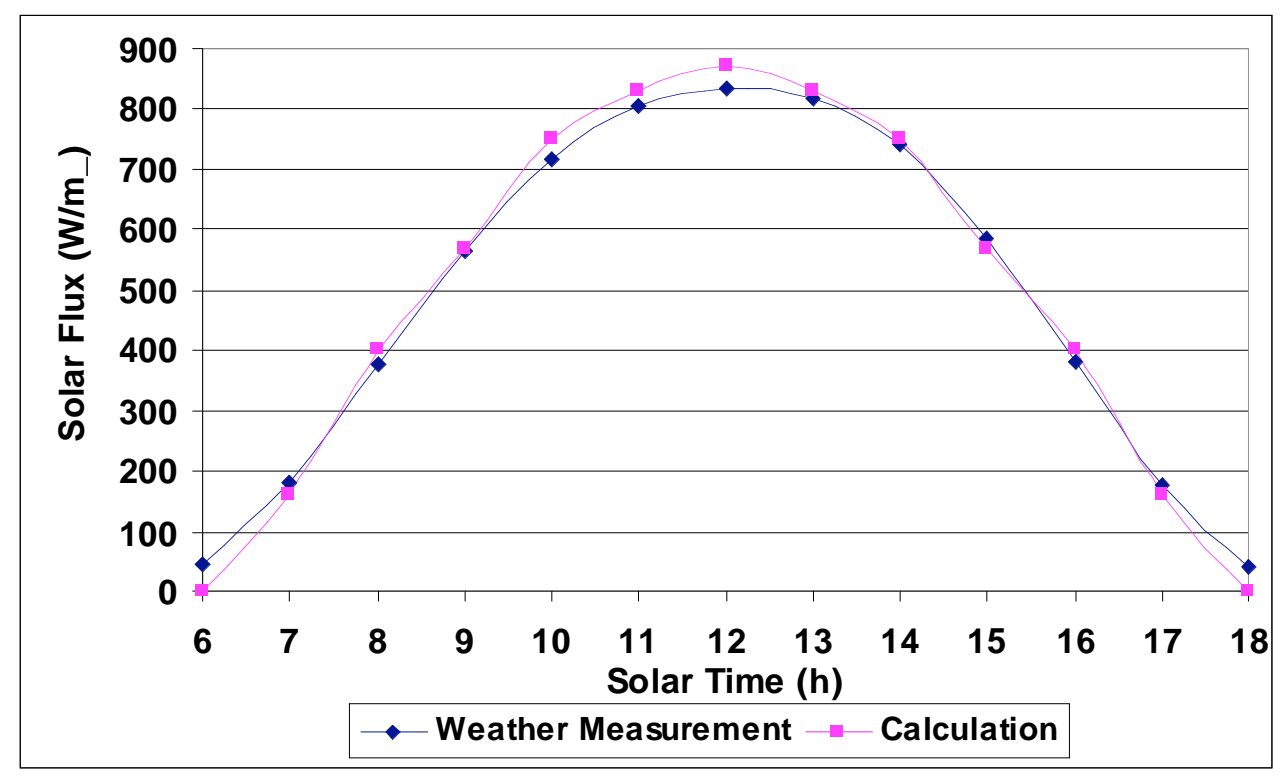

A2- Comparison compared to the data of quotes

All the year

The error on daily received energy remains within the limit of $\pm 10 \%$ between calculations and the tecsol software, and for the whole year the computed values according to the selected model of Bernard-Menguy-Schwartz only exceed the data of the Web site www.tecsol.fr of $3.3 \%$, what is too very acceptable.

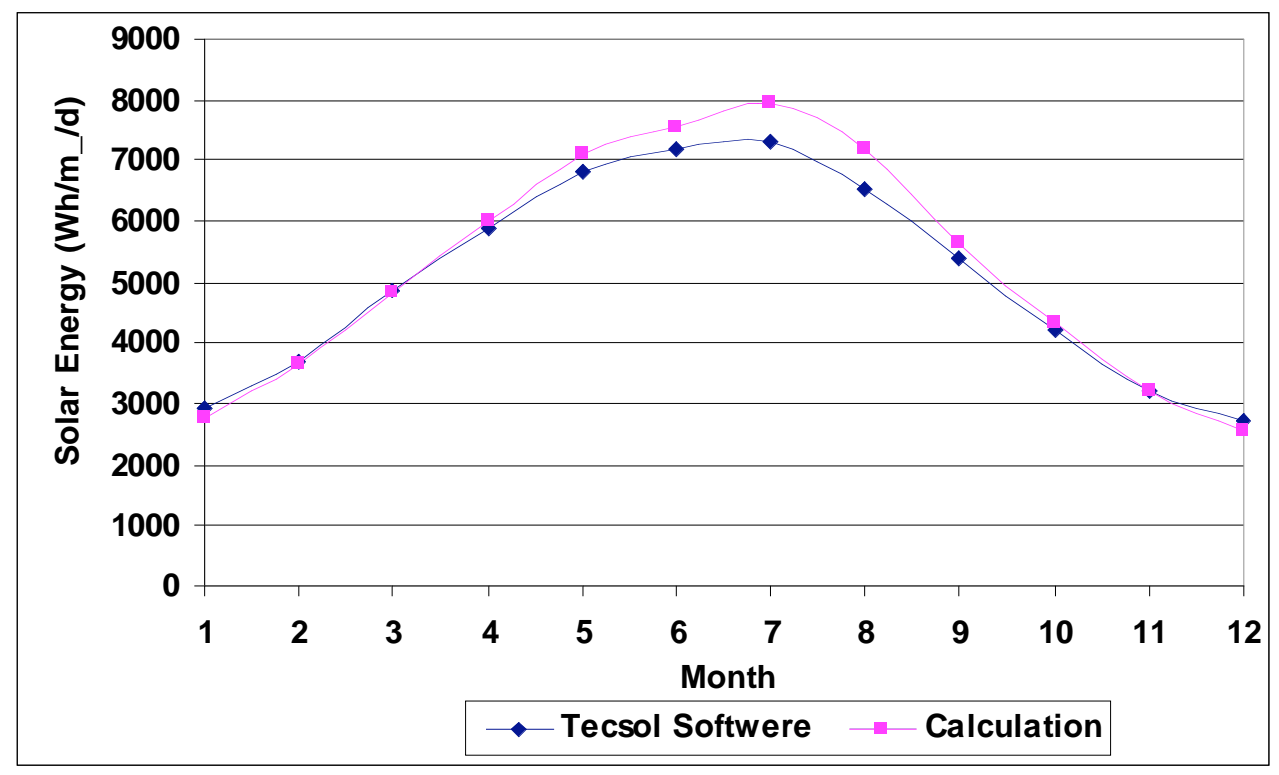




\section{REFERENCES}

[1] Henderson, D.; Junaidi, H.; Muneer, T. Experimental and CFD investigation of an ICSSWH at various inclinations. Renewable Sustain. Energy Rev., 2007, 11, 1087.

[2] Duffie, B. Solar Energy Thermal Process; Willey and Sounds: New York, 1974, p. 49.

[3] Brichambaut, CH. Solar Radiation, Natural Radiative Exchanges; Gautier Villars: Paris, 1963.

[4] Schwartz, B.M. The Solar Radiation, Thermal Conversion and Applications; Technique and Documentation, $21^{\text {st }}$ ed. Paris, 1980.

[5] Chasseriaux. Thermal Conversion of the Solar Radiation, Bordered: Paris, 1984.

[6] Sakkal, F.; Ghaddar, N.; Diab, J. Solar collectors for the Beirut climate. Appl. Energy, 1993, 45, 313.

[7] Morcos, V.H. Optimum tilt angle and orientation for solar collectors in Assiut. Egypt Renewable Energy, 1994, 4, 291-298.

[8] Sinjeri, L.J. Solar radiation on variously oriented collectors in Croatia. Renewable Energy, 1994, 4, 235.

[9] Hartley, L.E.; Martínez-Lozano, J.A.; Utrillas, M.P.; Tena, F., Pedrós, R. The optimisation of the angle of inclination of a solar collector to maximise the incident solar radiation. Renewable Energy, 1999, 17, 291.

[10] Yakup, M.A.; Malik, A.Q. Optimum tilt angle and orientation for solar collector in Brunei Darussalam. Renewable Energy, 2001, 24, 223.

[11] Shariah, A.; Al-Akhras, M.A.; Al-Omari, I.A. Optimizing the tilt angle of solar collectors. Renewable Energy, 2002, 26, 587.

[12] Mefti, A.; Bouroubi, M.Y.; Adane, A. Generation of hourly radiation for inclined surfaces using monthly mean sunshine duratioin in Algeria. Energy Convers. Manage., 2003, 44, 3125.

[13] Lingamgunta, C.; Veziroglu. T.N. A universal relationship for estimating daily clear sky insolation. Energy Convers. Manage., 2004, 45, 2313.
[14] Danny, H.W.; Joseph, C. Predicting solar irradiance on inclined surfaces using sky radiance data. Energy Convers. Manage., 2004, 45,3125 .

[15] Chow, T.T.; Chan, A.L.S. Numerical study of desirable solar collector orientations for the coastal region of South China. Appl. Energy, 2004, 79, 249.

[16] Al Mohamad, G. Direct and diffuse solar raduation in Syria. Appl. Energy, 2004, 79, 191.

[17] Elminir, H.K.; Ghitas, A.E.; ElHussainy, F. et al. Optimum solar frat-plate collector slope: case study for Helwan, Egypt. Energy Convers. Manage., 2006, 47, 624.

[18] Gunerhan, H.; Hepbasli, A. Determination of the optimum tilt angles of solar collectors for building applications. Build. Environ., 2007, 42, 779.

[19] Tang, R.; Wu, T. Optimal tilt-angles for solar collectors used in China. Appl. Energy, 2004, 79, 239.

[20] Ben Slama, R.; Riahi, S. On the choice of the angle of inclination of the solar collectors with water, case of Tunis. Tunisian Rev. Energy, 1993, 30,19.

[21] Ben Slama, R. Calculation and measurement of the incidental solar radiation on a solar collector. Tunisian Rev. Energy, 1997, 44, 37.

[22] Ben Slama, R. Solar Radiation Received at Tunis According to the Slope of the Solar Collector. Laws of Horizontal Measurements Conversion on an Inclined Plane. Proceeding of the 3rd International congress on Renewable Energy and Environment CERE. Mahdia Tunisia, November 6-8, 2006.

[23] Chauliagué, C. Solar Energy in the Building, Eyrolles. Paris, 1981, p. 119.

[24] Peri, G.; Afedes. Memosol: Mrandum of Heliotechnic; Europeen ed. Thermics and Industry, Paris, 1979.

[25] Hamdy, K.; Ahmed, E.E.; Ghitas, F.; El-Hussainy, R.; Hamid, M.M.; Beheary, Khaled, M. Abdel-Moneim. Optimum solar flatplate collector slope: case study for Helwan, Egypt. Energy Convers. Manage., 2006, 47, 624.

(C) Romdhane Ben Slama; Licensee Bentham Open.

This is an open access article licensed under the terms of the Creative Commons Attribution Non-Commercial License (http://creativecommons.org/licenses/by-nc/3.0/) which permits unrestricted, non-commercial use, distribution and reproduction in any medium, provided the work is properly cited. 